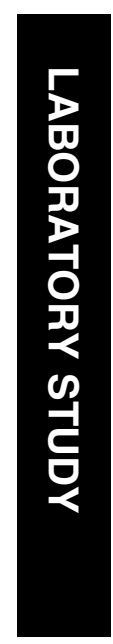

\title{
Intraocular pressure measurement in mice: a comparison between Goldmann and rebound tonometry
}

${ }^{1}$ Department of

Ophthalmology and Visual Sciences, The University of lowa, lowa City, IA, USA

\section{${ }^{2}$ Department of}

Ophthalmology, Institute of Vision Research, Yonsei University College of

Medicine, Seoul, Korea

${ }^{3}$ Department of Physiology and Biophysics, The University of lowa, lowa

City, lowa City, IA, USA

Correspondence:

MH Kuehn,

Departments of

Ophthalmology and Visual

Sciences,

University of lowa Hospitals and Clinics,

200 Hawkins Drive, 4120 MERF,

lowa City, IA 52242, USA

Tel: + 1319335 9565;

Fax: + 13193356641

E-mail: markus-kuehn@

uiowa.edu

Received: 7 April 2006 Accepted in revised form: 28 July 2006

Published online:

1 September 2006

\section{Abstract}

Purpose The development of mouse models of glaucoma requires methods to accurately measure the intraocular pressure (IOP) in this species. The aim of this study was to compare the accuracy of IOP measurements in mice between modified Goldmann and rebound tonometers.

Methods IOP was measured either with a modified Goldmann or a rebound tonometer while simultaneously measuring the IOP using invasive manometry in enucleated eyes and in vivo. The level of IOP was controlled hydrostatically. The agreement and correlation between the IOP determined by invasive manometry and by either noninvasive method was evaluated. In addition, the IOP was determined by both noninvasive methods in a cohort of mice with laser-induced ocular hypertension (OHT), and the agreement and correlation between the two tonometry methods were evaluated.

Results Measured IOP by either noninvasive tonometer correlated well with those recorded simultaneously by invasive manometry ( $r=0.98$ for rebound and $r=0.94$ for Goldmann). In mice with OHT, the IOP correlation between rebound and modified Goldmann was moderate $(r=0.71)$; the IOP measured by modified Goldmann tonometry was consistently higher than that by rebound by approximately $5 \mathrm{mmHg}$. However, the relative per cent increases in IOP were similar between the two methods.

Conclusion Both noninvasive methods of IOP measurements in mice are suitable to detect changes in IOP although rebound tonometry correlated better with the invasive manometry readings. The results suggest that the relative, rather than absolute, IOP offers a
CY Kim ${ }^{1,2}, \mathrm{MH}$ Kuehn ${ }^{1}, \mathrm{MG}$ Anderson ${ }^{3}$ and $\mathrm{YH} \mathrm{Kwon}{ }^{1}$ more reliable means of correlating findings from studies using different tonometers. Eye (2007) 21, 1202-1209; doi:10.1038/sj.eye.6702576; published online 1 September 2006

Keywords: IOP measurement; IOP correlation; modified Goldmann tonometer; mouse; rebound tonometer

\section{Introduction}

Glaucoma is one of the most common causes of vision loss worldwide. ${ }^{1,2}$ Despite the clinical significance of the disease, many aspects of its pathophysiology remain unresolved and are under ongoing investigation. Further elucidation of the mechanisms involved in glaucomatous optic neuropathy will be greatly facilitated by the availability of reliable animal models of the disease. Mouse models of glaucoma have recently been described ${ }^{3-7}$ and represent a particularly attractive model owing to the ease of husbandry, the extensive genomic resources available for this species, and the potential for genetic manipulation. ${ }^{8}$ As the level of intraocular pressure (IOP) is a major risk factor in glaucoma, ${ }^{9}$ accurate determination of IOP is important in experimental glaucoma models. However, owing to the small size of the mouse eye IOP measurements in mice are challenging. Reliable and precise measurements of IOP in mice can be obtained by cannulation of the anterior chamber and a direct measurement using a pressure transducer. ${ }^{10-13}$ This method is invasive and only a very limited number of measurements can be taken from the same eye. Consequently, several noninvasive methods for IOP measurements in mice have been developed, including rebound, ${ }^{14,15}$ 
modified Goldmann, ${ }^{4,16}$ and other types of tonometry. ${ }^{5,17,18}$ How well IOP measurements in mice obtained by these various noninvasive methods correlate to one other has not been reported, making direct comparison and interpretation of data from laboratories using different methods of tonometry difficult. In order to address this issue and to determine if one method of noninvasive IOP measurement is superior to others, we systematically compared the accuracy and reproducibility of measurements obtained by two methods of IOP measurements in mice: modified Goldmann $\left(\mathrm{IOP}_{\mathrm{G}}\right)$ and rebound tonometry $\left(\mathrm{IOP}_{\mathrm{R}}\right)$.

\section{Materials and methods}

All animals were treated in accordance with the ARVO statement for Use of Animals in Ophthalmic and Vision Research, and procedures were approved by the University of Iowa Committee on Animal Care. C57BL/ $6 \mathrm{~J}$ mice obtained from The Jackson Laboratory were used for these studies. Mice were kept under a regimen of $12 \mathrm{~h}$ of light and $12 \mathrm{~h}$ of darkness and all measurements in live animals were performed between 1000 and 1300 hours to minimize the effect of diurnal IOP variation. IOP was determined in a laboratory located adjacent to the housing facilities to minimize stress owing to transport. All measurements in vivo were carried out under inhalation anaesthesia using $2 \%$ isoflurane (Phoenix, St Joseph, MO, USA) and $100 \%$ oxygen.

\section{Simultaneous invasive and noninvasive IOP measurements}

Simultaneous invasive and noninvasive measurements were carried out both in enucleated mouse eyes $(n=12)$, obtained immediately after death, and in the eyes $(n=8)$ of live animals. Half of the eyes were used for $\mathrm{IOP}_{\mathrm{G}}$ measurements; the other half was used for the determination of $\mathrm{IOP}_{\mathrm{R}}$. Several tonometer readings were obtained from each eye while varying amounts of hydrostatic pressure were applied and the pressure was continuously monitored invasively $\left(\mathrm{IOP}_{\mathrm{IN}}\right)$ by direct cannulation. Each measurement consisted of several readings (see below) and averages of these readings are used throughout this paper.

IOP measurements in enucleated eyes and live animals were carried out in a similar manner except that enucleated eyes were mounted in a custom-built stand. Two 26-gauge steel needles were carefully inserted into the posterior segment of the eye, and care was taken to avoid contact with the lens. One needle was connected to a pressure transducer (MLTO380, ADInstruments, Colorado Springs, CO), while the other was connected to a phosphate buffer solution (PBS) infusion bottle that could be raised or lowered to establish various levels of hydrostatic pressure. Before experimentation, we ascertained that the insertion of the needles did not noticeably displace the lens and determined that the transduction of pressure through both needles was unimpeded by raising and lowering the PBS bottle several times.

Measurements were carried out in a masked manner: one investigator selected the elevation of the PBS bottle and recorded the IOP as determined by invasive manometry, while a second investigator (CYK) measured the IOP using either a rebound tonometer (Tonolab tonometer, Colonial Medical Supply, Franconia, NH) or a modified Goldmann tonometer (Haag-Streit USA Inc., Mason, $\mathrm{OH}, \mathrm{USA}$ ) as reported previously.,16

Twelve IOP $\mathrm{R}_{\mathrm{R}}$ or five $\mathrm{IOP}_{\mathrm{G}}$ tonometry, and twelve IOP measurements were taken and the mean IOP was calculated. In a small number of eyes, it became technically impossible to take this number of measurements (eg due to needle occlusion or excessive leakage around the cannulation needle etc); however, a minimum of three Goldmann or six rebound measurements was always obtained and used for analysis. Data derived in vivo and from enucleated eyes were analysed independently.

\section{Laser-induction of ocular hypertension (OHT)}

Laser photocoagulation to the limbus in the area of the trabecular meshwork was performed as reported previously. ${ }^{4}$ Briefly, mice were anesthetized with $2 \%$ isoflurane and $100 \%$ oxygen. A $3 \mu$ l portion of indocyanine green $(10 \mathrm{mg} / \mathrm{ml}$; Akorn, Buffalo Grove, IL, USA) was slowly injected into the anterior chamber of the eye using a micro-injector pump (World Precision Instruments, Sarasota, FL, USA). Twenty minutes after the injection, a diode laser (DioVet, Iridex Corporation, Mountain View, CA, USA) was used to deliver between 30-35 spots exteriorly over a $300^{\circ}$ range of the limbus outlined by the dye (200-300 mW energy, 200-300 ms pulse duration). Following the procedure, antibiotic ointment was applied over the eye and acetaminophen $(240 \mathrm{mg} / \mathrm{l})$ and codeine $(24 \mathrm{mg} / \mathrm{l})$ were administered in the drinking water for 7 days. In each case, the left eye underwent laser surgery and the untreated right eye was used as the control.

\section{Comparison of noninvasive IOP measurements in mice with $\mathrm{OHT}$}

IOP measurements by rebound and Goldmann tonometer were taken in 46 mice with laser-induced OHT preoperatively and 1, 3, 7, and 14 days after laserphotocoagulation. IOP measurements were taken in 
random order in both laser-induced and control eyes. Twelve rebound and five Goldmann readings were obtained for each eye on every examination day and the mean was used for further calculation. As the fluorescent dye (Fluorescent Sodium $0.25 \%$ and Benoxinate Hydrochloride $0.4 \%$ Ophthalmic, Bausch \& Lomb, Tampa, FL, USA) necessary for Goldmann tonometry renders the surface of the eye slightly sticky and interferes with accurate rebound tonometry, rebound tonometry was always performed first, followed by Goldmann usually within $1 \mathrm{~h}$ of rebound tonometry measurement. All noninvasive tonometry measurements were taken by the same investigator (CYK) to eliminate interobserver differences.

\section{Statistical analysis}

Differences of IOP after induction of anaesthesia were evaluated by Kruskal-Wallis test and Wilcoxon signed rank test as a substitute for post hoc analysis.

IOP measurements between both noninvasive and invasive tonometers were evaluated by correlation analysis and calculation of the limit of agreement as described by Bland and Altman. ${ }^{19}$

Student's paired $t$-test was used to evaluate the differences in IOP between control and laser-treated eyes on each exam day. This test was also used to evaluate the differences in relative IOP elevation measured by $\mathrm{IOP}_{\mathrm{G}}$ and $\mathrm{IOP}_{\mathrm{R}}$.

All statistical analyses were carried out using SPSS version 11.5 software or Microsoft Excel.

\section{Results}

\section{Influence of inhalation anaesthesia on mouse IOP}

Anaesthesia has been shown to influence IOP in rodents and therefore we initially determined the time course of isoflurane-induced IOP changes. For this study, mice $(n=12)$ were anesthetized with $2 \%$ isoflurane $+100 \%$ oxygen and monitored for the loss of lid reflex, which typically occurred within $1 \mathrm{~min}$. At this point, and every 5 min thereafter, 12 measurements of IOP were obtained from each animal with the rebound tonometer (Figure 1). Measured mean IOP decreases rapidly from 14.1 to $9.9 \mathrm{mmHg}$ during the first $10 \mathrm{~min}$ after loss of lid reflex but remains unchanged thereafter $(P=0.508$ for changes between 10 and $15 \mathrm{~min}$, Wilcoxon signed rank test). Based upon these findings, all subsequent IOP readings in animals were carried out after a waiting period of at least $10 \mathrm{~min}$ in order to allow the IOP to stabilize.

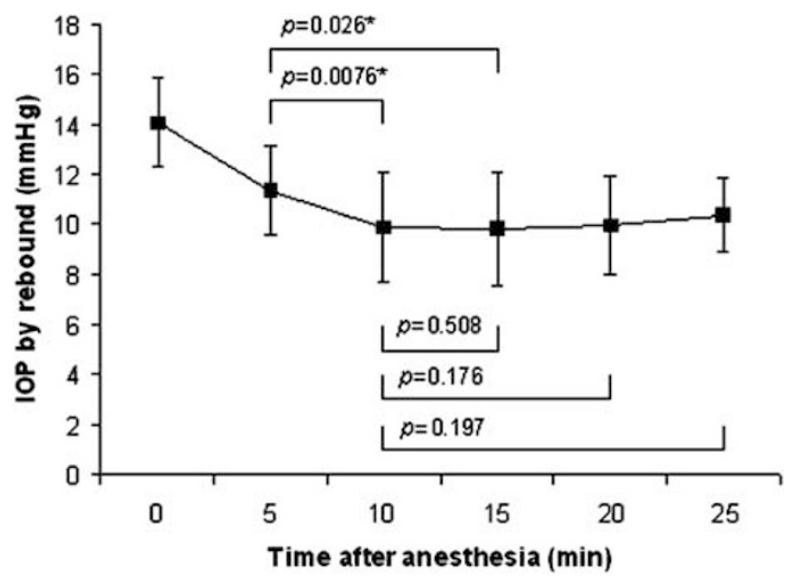

Figure 1 IOP changes in mice $(n=12)$ during inhalation anaesthesia measured by rebound tonometry. IOP stabilizes approximately $10 \mathrm{~min}$ after the loss of lid reflex (error bars represent $\mathrm{SD}) .\left({ }^{*} P<0.05\right.$ by Wilcoxon signed rank test).

\section{Correlation of IOP measurements obtained by invasive and noninvasive methods}

One of the aims of this study was to compare the degree of accuracy and reproducibility of IOP measurements in mice obtained through either a modified Goldmann tonometer or rebound tonometer. As Goldmann tonometry requires the positioning of the eye or animal behind a slit-lamp, measurements of the same eye with both instruments are impossible to obtain without movement of the experimental set-up resulting in possibly altered hydrostatic pressure. Accordingly, $\mathrm{IOP}_{\mathrm{G}}$ and $\mathrm{IOP}_{\mathrm{R}}$ measurements were carried out independently and correlated to those obtained by direct invasive $\mathrm{IOP}_{\mathrm{IN}}$.

In enucleated mouse eyes, data obtained through either noninvasive method correlated well to those obtained through direct, invasive measurements (Figure 2). Analyses of the relation between $\mathrm{IOP}_{\mathrm{IN}}$ and $\operatorname{IOP}_{\mathrm{R}}(r=0.99)$ as well as between $\mathrm{IOP}_{\mathrm{IN}}$ and $\mathrm{IOP}_{\mathrm{G}}$ $(r=0.94)$ demonstrated that measurements taken by either instrument are very well correlated to the $\mathrm{IOP}_{\mathrm{IN}}$. In the Bland-Altman assessment of agreement, the average difference between $\mathrm{IOP}_{\mathrm{IN}}$ and $\mathrm{IOP}_{\mathrm{G}}$ was $0.5 \mathrm{mmHg}$, and the $95 \%$ of limit of agreement, defined as the mean $\mathrm{IOP} \pm 2 \mathrm{SD}$, ranged from -6.3 to $7.2 \mathrm{mmHg}$ (Figure 2). In the analysis of agreement between $\mathrm{IOP}_{\mathrm{IN}}$ and $\mathrm{IOP}_{\mathrm{R}}$, the average difference was $-0.8 \mathrm{mmHg}$, and the $95 \%$ limit of difference $(2 \mathrm{SD}=3.7 \mathrm{mmHg})$ ranged from -4.5 to $2.9 \mathrm{mmHg}$ (Figure 2).

As it was conceivable that enucleation of the mouse eye and subsequent mounting in the measuring apparatus affected one method of tonometry more than the other, additional measurements were obtained in vivo from anesthetized mice and independently analysed (Figure 3). Data obtained in vivo were very similar to 

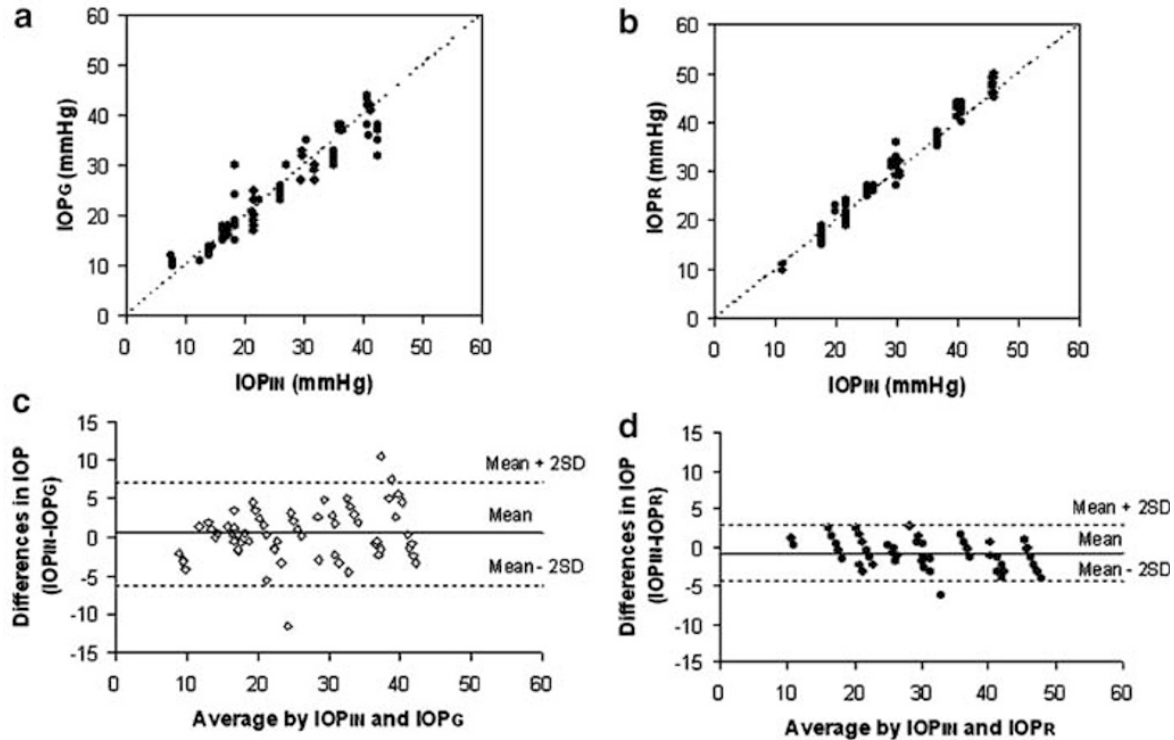

Figure 2 Relationship between invasive and noninvasive measurements of IOP in enucleated mouse eyes $(n=6$ for each noninvasive tonometer). Data analyses suggests a good correlation between $\operatorname{IOP}_{\mathrm{IN}}$ and (a) $\operatorname{IOP}_{\mathrm{G}}(r=0.94)$ or (b) $\operatorname{IOP}_{\mathrm{R}}(r=0.99)$. Further evaluation by Brand-Altman analysis demonstrates that the $95 \%$ limit of agreement (dotted lines) is larger for the Goldmann tonometer (c) than for the rebound tonometer $(\mathrm{d})$.

a
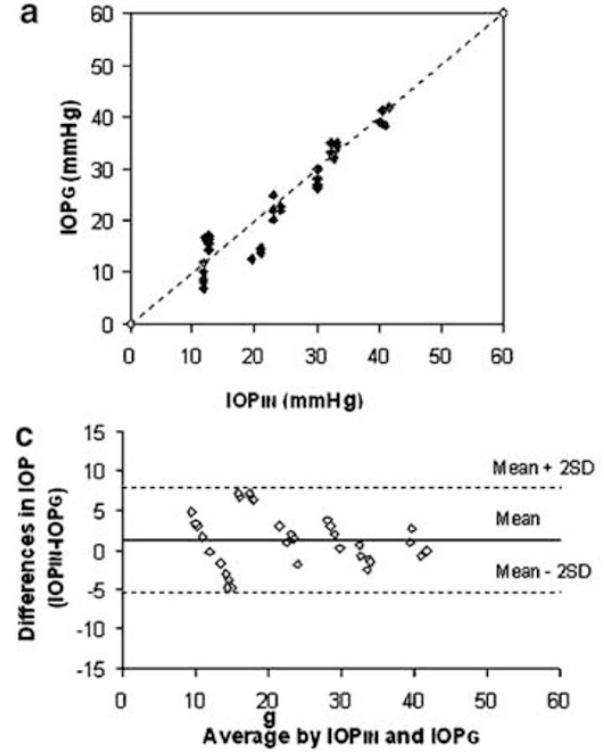

b
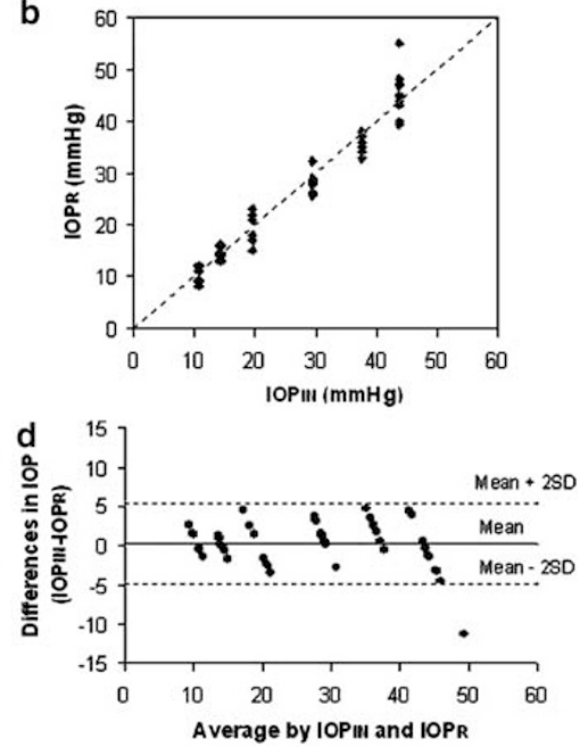

Figure 3 Relationship between invasive and noninvasive measurements of IOP in vivo mice ( $n=4$ in each noninvasive tonometer) under general anaesthesia. Under the employed conditions, $\operatorname{IOP}_{\mathrm{IN}}$ is strongly correlated to both $\operatorname{IOP}_{\mathrm{G}}(\mathrm{a}, r=0.94)$ and $\mathrm{IOP}_{\mathrm{R}}(\mathrm{b}, r=0.98)$. The 95\% limits of agreement (dotted lines) for both Goldmann (c) and rebound (d) were similar to those observed in enucleated eyes in vitro.

those obtained in enucleated eyes both for rebound $\left(\mathrm{IOP}_{\mathrm{IN}}\right.$ and $\mathrm{IOP}_{\mathrm{R}} r=0.98$, average differences $=0.2 \mathrm{mmHg}$, $95 \%$ limit of differences $-5.0-5.4 \mathrm{mmHg}$ ) and Goldmann tonometry ( $\mathrm{IOP}_{\mathrm{IN}}$ and $\mathrm{IOP}_{\mathrm{G}} r=0.94$, average differences $=1.3 \mathrm{mmHg}$, $95 \%$ limit of differences
-5.3 to $7.8 \mathrm{mmHg})$. In addition, there was greater mean offset $(1.3 \mathrm{mmHg})$ of the Goldmann pressure with respect to the invasive manometry than that $(0.2 \mathrm{mmHg})$ of the rebound pressure (Figure 3). Taken together, our data suggest that rebound tonometry is better correlated with 
invasive manometry and delivers tighter correlation than Goldman tonometry in mice.

\section{Correlation of noninvasive tonometry in mice with OHT}

We further sought to directly evaluate the correlation between $\mathrm{IOP}_{\mathrm{G}}$ and $\mathrm{IOP}_{\mathrm{R}}$ in vivo in a setting that mimics laboratory conditions using a population of mice with a range of IOPs. In order to induce different degrees of IOP, we induced OHT in a cohort of animals $(n=46)$ by diode laser cauterization of the trabecular meshwork. Using the methods described above, laser cauterization resulted in moderate elevation of IOP in operated eyes 1 day after laser treatment when compared to control eyes $\left(P=7.18 \times 10^{-10}\right.$ in Goldmann tonometer and $P=3.57 \times 10^{-15}$ in rebound tonometer, paired $t$-test), and IOP elevation in the laser-treated eye persisted throughout the 2-week observation period (Figure $4 \mathrm{a}$ and $\mathrm{b}, P<0.001$ in both tonometers). The preoperative mean IOP $( \pm S D)$ of all eyes was $16.3 \pm 1.5 \mathrm{mmHg}$ by Goldmann tonometry and $11.3 \pm 2.0 \mathrm{mmHg}$ when determined by rebound tonometry $\left(P=8.03 \times 10^{-27}\right)$. This difference in tonometer readings of approximately $5 \mathrm{mmHg}$ was also evident at each subsequent examination time point. The correlation between $\mathrm{IOP}_{\mathrm{G}}$ and $\mathrm{IOP}_{\mathrm{R}}$ was moderate $(r=0.70)$ (Figure $4 \mathrm{c}$ ) and the limit of agreement was large (mean difference $4.8 \mathrm{mmHg}$, $95 \%$ limit of agreement $-0.6-10.3 \mathrm{mmHg}$ ). However, the overall IOP increase following laser treatment and the subsequent slow decline of IOP was clearly evident regardless of the measurement method. When the average per cent increase in IOP of laser-treated vs control eyes was analysed, both methods yielded more similar data (Day 0, $P=0.92$; Day $1, P=0.01$; Day 3, $P=0.80$; Day $7, P=0.99$, and Day $14, P=0.25$ )

(Figure 4d).

\section{Discussion}

Elevated IOP is a significant risk factor for the development of glaucoma, and the accurate determination of IOP is one of the most important clinical tools in the management of the disease. Since its introduction in the 1950s, the Goldmann applanation tonometer has been one of the most popular methods of measuring IOP and it has become the standard for clinical practice. ${ }^{20,21}$ Modifications of the applanation biprism angle and applied weight have been recently described that allow measurement of IOP in mice using this instrument. ${ }^{16}$ The rebound tonometer used in this study is a relatively new device based on similar physical principles as the vibration tonometer. ${ }^{22,23}$ Reports of
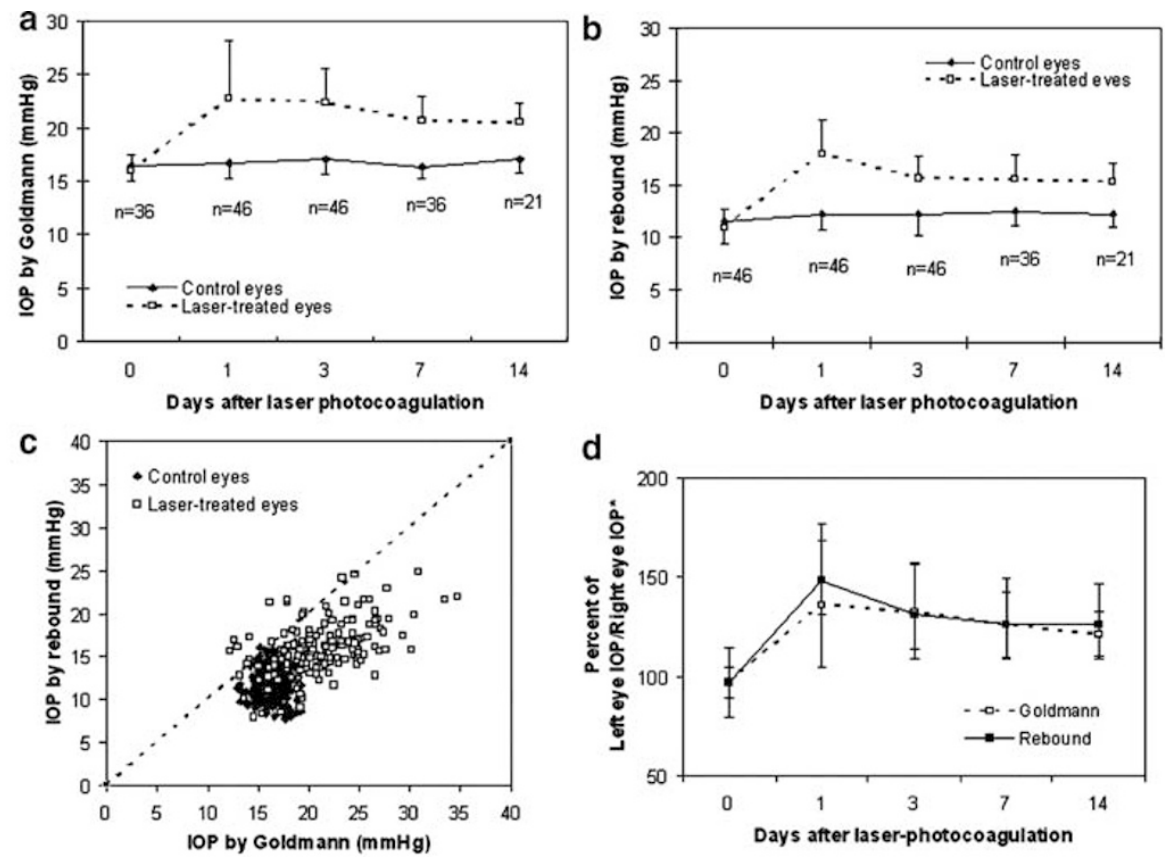

d

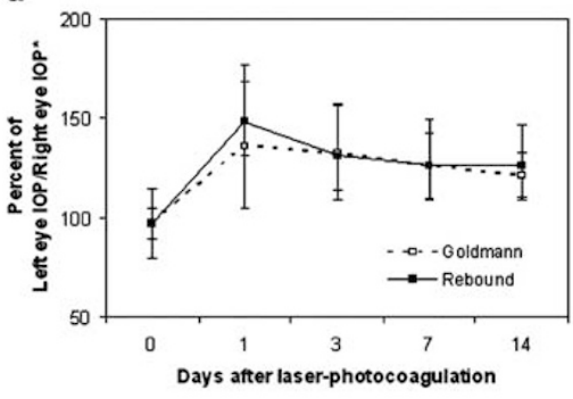

Figure 4 IOP changes in mouse eyes measured by (a) Goldmann and (b) rebound tonometry after laser treatment. Laser cauterization resulted in moderate elevation of IOP in operated eyes 1 day after laser treatment when compared to control eyes, and IOP elevation in the laser-treated eye persisted throughout the 2-week observation period $(P<0.001$ in both tonometers). (c) Data obtained are moderately correlated and suggest that IOP measured by Goldmann are typically higher than those by rebound (The line of equality is depicted as a dotted line). (d) Relative increase of IOP as determined by the two methods. 
rebound tonometer use in rats,,$^{15,24}$ mice, ${ }^{14,15,25}$ and human patients ${ }^{26,27}$ demonstrated that this type of tonometer is convenient to use and yields reliable data.

The data obtained in this study further confirm that good correlation between $\mathrm{IOP}_{\mathrm{IN}}$ and both $\mathrm{IOP}_{\mathrm{G}}$ and $\mathrm{IOP}_{\mathrm{R}}$ can be demonstrated in mouse eyes. Our data further demonstrate that in mice the rebound tonometer outperforms the modified Goldmann tonometer both in terms of the correlation to invasively measured IOP and in the ease of use. However, Bland-Altman analyses ${ }^{19}$ demonstrate that even for the rebound tonometer the margins of error are not trivial and suggest that several repeated measurements should be taken.

One difficulty in the direct comparison of these two types of tonometers lies in the fact that we, and others, ${ }^{16}$ observed a mild but consistent decline in IOP values when numerous Goldmann readings were obtained serially from the same mouse eye in vivo. This decline is possibly an artefact induced by the displacement of aqueous humor as a result of undue pressure applied by the tonometer tip to a large portion of the mouse cornea. This effect was not observed in cannulated eyes where the IOP was maintained hydrostatically and was also not evident during rebound tonometry, in contrast to recently published reports by Morris et al..$^{25}$ Regardless of the cause, this observation suggests that in vivo a large number of Goldmann readings are unlikely to improve accuracy. We found that up to five Goldmann readings can be obtained with relatively minor decline in measured IOP and accordingly this number of measurements were taken for this study. In contrast, a large number of rebound measurements are possible without apparent decline in measured IOP. The data presented here represent the average of 12 serial measurements; a number which can easily be obtained in most studies. The higher number of rebound readings per measurement likely contributes to the increased accuracy of rebound tonometry. However, for the reasons pointed out above, the limited number of readings that can be obtained by Goldmann tonometry does impose a practical limitation on the accuracy of this method in mice.

The difficulty of obtaining reliable readings through the use of the modified Goldmann may further be explained by several differences between the human and mouse tonometer and the human and mouse eye. The fraction of the applanated area to the total cornea is $25 \%$ in human and $44.1 \%$ in mouse. ${ }^{16}$ As the accuracy of the Goldmann readings is influenced by many corneal factors including corneal thickness, structure, and oedema ${ }^{20}$ applanation tonometry in the mouse may be more susceptible to corneal factors due to the high proportion of the applanated area. The relatively high ratio of the applanated area in conjunction with the small size of the mouse eye also interferes with the ability to appropriately focus the measuring prism on the eye. If the Goldmann prism tip is not perfectly aligned with the axis of the eye, the fluorescent rings do not move properly when the measuring drum on the tonometer is turned. The modified Goldmann tonometer has only a very narrow range of acceptable contact positions which makes it challenging to determine when the edges of both fluorescent rings are in the correct position (Figure 5) and may contribute to the greater difficulty of obtaining reliable data using this method.

Given the margins of error between both $\mathrm{IOP}_{\mathrm{IN}}$ and $\mathrm{IOP}_{\mathrm{R}}$ and between $\mathrm{IOP}_{\mathrm{IN}}$ and $\mathrm{IOP}_{\mathrm{G}}$, the observed moderate correlation between $\mathrm{IOP}_{\mathrm{R}}$ and $\mathrm{IOP}_{\mathrm{G}}$ in the mice with OHT was to be expected. However, our finding that Goldmann readings were consistently higher than those obtained by the rebound tonometer by approximately $5 \mathrm{mmHg}$ was not anticipated. Average IOP $_{\mathrm{G}}$ of all normal eyes of sedated C57BL/6 $\mathrm{J}$ mice was $16.3 \mathrm{mmHg}$,

approximately $5.0 \mathrm{mmHg}$ higher than the average $\mathrm{IOP}_{\mathrm{R}}$ for the same eyes and roughly the same difference in IOP readings was noticeable at all subsequent measurements. Despite the difference in absolute IOP, the relative IOP increase between control eyes and laser-cauterized OHT eyes was very similar between both instruments. These findings suggest that both methods are capable of accurately determining pressure changes within the
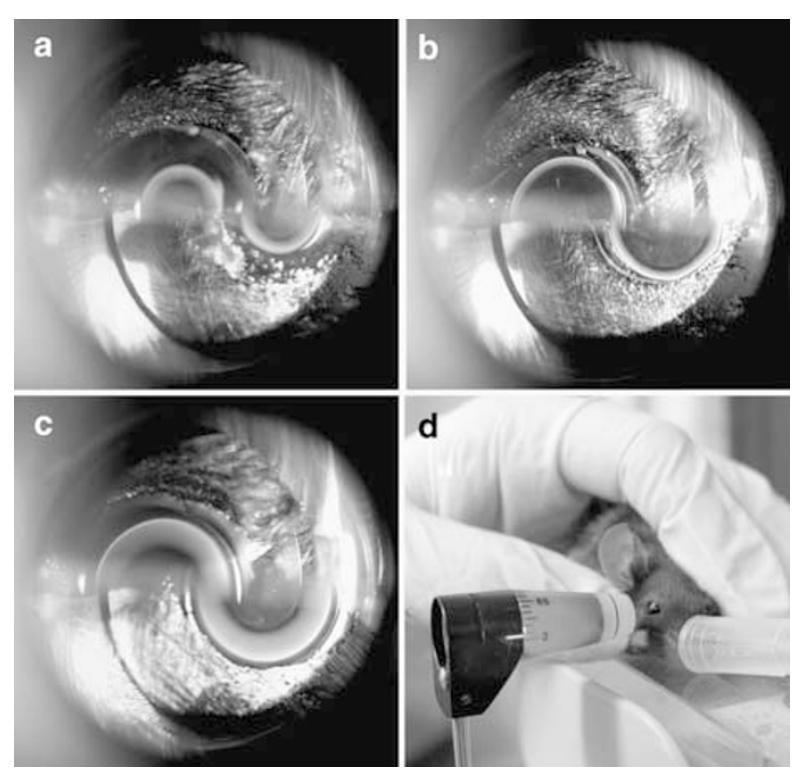

Figure 5 Fluorescent rings during IOP measurement in mice using a modified Goldmann tonometer. (a) Setting of measuring drum is too low. (b) Appropriate position and width of the fluorescent ring for correct IOP measurement. (c) The width of the fluorescent ring is too thick, leading to overestimation of IOP. (d) Mouse position during IOP measurement by Goldmann tonometer. 
same study, even though the comparison between absolute measurements obtained from different instruments may not be directly comparable.

It is unclear why the Goldmann IOP measurements are consistently higher than rebound tonometry in vivo. Based upon the difference of each tonometer to invasive IOP measurements, we would have expected a difference of approximately $1 \mathrm{mmHg}$ higher IOP by Goldmann than by rebound tonometer instead of the observed difference of approximately $5 \mathrm{mmHg}$. How can this IOP difference be explained? (1) It is conceivable that the order in which the measurements were taken (rebound before Goldmann) altered IOP directly, or corneal properties which in turn might affect IOP measurements indirectly. However, when the IOP of normal mouse eyes is determined with either method alone, without prior use of the other tonometer, values obtained were similar to those presented in this study (data not shown). Thus, it seems unlikely that rebound tonometry significantly affected the IOP or the corneal properties. (2) It is conceivable that there were changes in the corneal thickness following laser treatment owing to inflammation that affected Goldmann more than rebound tonometry. However, the difference of $5 \mathrm{mmHg}$ was present even before the laser treatment as well as in the fellow, untreated eye. (3) During Goldmann tonometry, the mouse head needs to be restrained and the eyelids need to be sufficiently retracted to allow applanation of $44 \%$ of the corneal surface ${ }^{16}$ (Figure 5). This manipulation may unduly apply pressure on the globe, analogous to applanating a patient with narrow palpebral fissure. This extra pressure on the globe does not occur during experiments where simultaneous invasive manometry is performed because the eyelid and globe are all relatively fixed in position by the invasive manometry needles. In contrast, no manipulation of the lids is required for rebound tonometry. (4) Noninvasive measurement by rebound tonometry (without stabilization by manometry needles) may lead to underestimation of the IOP due to a cushioning effect by the periorbital tissue or respiratory movements. This underestimation is minimized by the insertion of the manometry needles that fixate the globe in a firm position. Our findings that rebound tonometry tends to measure lower pressures than Goldmann tonometry in mice is in contrast to studies that suggest overestimation of IOP by the rebound tonometer when compared to Goldmann in human patients. ${ }^{25}$ However, it is difficult to compare IOP measurements between species and different instruments.

The notion that rebound tonometry may underestimate the IOP in mice is supported by other studies. Sedation of mice lowers IOP, and the magnitude of this effect varies between the types and amount of anaesthesia used, ${ }^{28}$ making direct comparison between published data problematical. Savinova et $a l^{11}$ Danias et $a l^{14}$ and Wang et $a l^{15}$ all determined the IOP of C57BL/ 6J mice under xylazine/ketamine sedation followed by IOP measurements either by cannulation alone or by simultaneous cannulation and rebound tonometry. The data reported by these groups for the normal IOP in C57BL $/ 6$ mice $\left(\mathrm{IOP}_{\mathrm{IN}}=13.1 \mathrm{mmHg}^{5}{ }^{5} \mathrm{IOP}_{\mathrm{R}}=9.2\right.$ and $9.8 \mathrm{mmHg}^{14,15}$ ) suggest that rebound tonometry in mice in vivo may underestimate the IOP.

In summary, our data demonstrate that both noninvasive tonometers yield reliable data, although we found rebound tonometry to be both more convenient and accurate to use. In comparison of mice with OHT, measurements obtained by Goldmann tonometry were higher than those by rebound tonometry. However, the relative pressure increase (laser-treated eye to control eye) was similar between both methods. The results suggest that the relative pressure, rather than absolute IOP, offers a more reliable means of correlating findings from studies using different tonometers.

\section{References}

1 Quigley HA. Number of people with glaucoma worldwide. Br J Ophthalmol 1996; 80(5): 389-393.

2 Leske MC. The epidemiology of open-angle glaucoma: a review. Am J Epidemiol 1983; 118(2): 166-191.

3 Aihara M, Lindsey JD, Weinreb RN. Experimental mouse ocular hypertension: establishment of the model. Invest Ophthalmol Vis Sci 2003; 44(10): 4314-4320.

4 Grozdanic SD, Betts DM, Sakaguchi DS, Allbaugh RA, Kwon YH, Kardon RH. Laser-induced mouse model of chronic ocular hypertension. Invest Ophthalmol Vis Sci 2003; 44(10): 4337-4346.

5 Gross RL, Ji J, Chang P, Pennesi ME, Yang Z, Zhang J et al. A mouse model of elevated intraocular pressure: retina and optic nerve findings. Trans Am Ophthalmol Soc 2003; 101: 163-169 (discussion 169-171).

6 John SW, Smith RS, Savinova OV, Hawes NL, Chang B, Turnbull D et al. Essential iris atrophy, pigment dispersion, and glaucoma in DBA/2J mice. Invest Ophthalmol Vis Sci 1998; 39(6): 951-962.

7 Sheldon WG, Warbritton AR, Bucci TJ, Turturro A. Glaucoma in food-restricted and ad libitum-fed DBA/2NNia mice. Lab Anim Sci 1995; 45(5): 508-518.

8 Weinreb RN, Lindsey JD. The importance of models in glaucoma research. J Glaucoma 2005; 14(4): 302-304.

9 Shields M, Ritch R, Krupin T. Classification of glaucoma. In: Ritch R, Shields M, Krupin T (eds). The Glaucomas. Mosby: St Louis, 1996 pp 717-725.

10 John SW, Hagaman JR, MacTaggart TE, Peng L, Smithes O. Intraocular pressure in inbred mouse strains. Invest Ophthalmol Vis Sci 1997; 38(1): 249-253.

11 Savinova OV, Sugiyama F, Martin JE, Tomarev SI, Paigen BJ, Smith RS et al. Intraocular pressure in genetically distinct mice: an update and strain survey. BMC Genet 2001; 2: 12. 
12 Aihara M, Lindsey JD, Weinreb RN. Reduction of intraocular pressure in mouse eyes treated with latanoprost. Invest Ophthalmol Vis Sci 2002; 43(1): 146-150.

13 Avila MY, Carre DA, Stone RA, Civan MM. Reliable measurement of mouse intraocular pressure by a servo-null micropipette system. Invest Ophthalmol Vis Sci 2001; 42(8): 1841-1846.

14 Danias J, Kontiola AI, Filippopoulos T, Mittag T. Method for the noninvasive measurement of intraocular pressure in mice. Invest Ophthalmol Vis Sci 2003; 44(3): 1138-1141.

15 Wang WH, Millar JC, Pang IH, Wax MB, Clark AF. Noninvasive measurement of rodent intraocular pressure with a rebound tonometer. Invest Ophthalmol Vis Sci 2005; 46(12): 4617-4621.

16 Cohan BE, Bohr DF. Measurement of intraocular pressure in awake mice. Invest Ophthalmol Vis Sci 2001; 42(11): 2560-2562.

17 Reitsamer HA, Kiel JW, Harrison JM, Ransom NL, McKinnon SJ. Tonopen measurement of intraocular pressure in mice. Exp Eye Res 2004; 78(4): 799-804.

18 Avila MY, Munera A, Guzman A, Do CW, Wang Z, Stone RA et al. Noninvasive intraocular pressure measurements in mice by pneumotonometry. Invest Ophthalmol Vis Sci 2005; 46(9): 3274-3280.

19 Bland JM, Altman DG. Statistical methods for assessing agreement between two methods of clinical measurement. Lancet 1986; 1(8476): 307-310.

20 Whitacre MM, Stein R. Sources of error with use of Goldmann-type tonometers. Surv Ophthalmol 1993; 38(1): $1-30$.
21 Dielemans I, Vingerling JR, Hofman A, Grobbee DE, de Jong PT. Reliability of intraocular pressure measurement with the Goldmann applanation tonometer in epidemiological studies. Graefes Arch Clin Exp Ophthalmol 1994; 232(3): 141-144.

22 Kontiola A. A new electromechanical method for measuring intraocular pressure. Doc Ophthalmol 1996; 93(3): 265-276.

23 Kontiola AI. A new induction-based impact method for measuring intraocular pressure. Acta Ophthalmol Scand 2000; 78(2): 142-145.

24 Kontiola AI, Goldblum D, Mittag T, Danias J. The induction/impact tonometer: a new instrument to measure intraocular pressure in the rat. Exp Eye Res 2001; 73(6): 781-785.

25 Morris CA, Crowston JG, Lindsey JD, Danias J, Weinreb RN. Comparison of invasive and non-invasive tonometry in the mouse. Exp Eye Res 2006; 82(6): 1094-1099.

26 Kontiola A, Puska P. Measuring intraocular pressure with the Pulsair 3000 and Rebound tonometers in elderly patients without an anesthetic. Graefes Arch Clin Exp Ophthalmol 2004; 242(1): 3-7.

27 Martinez-de-la-Casa JM, Garcia-Feijoo J, Castillo A, Garcia-Sanchez J. Reproducibility and clinical evaluation of rebound tonometry. Invest Ophthalmol Vis Sci 2005; 46(12): $4578-4580$.

28 Jia L, Cepurna WO, Johnson EC, Morrison JC. Effect of general anesthetics on IOP in rats with experimental aqueous outflow obstruction. Invest Ophthalmol Vis Sci 2000; 41(11): 3415-3419. 